\title{
Laryngeal Adenoid Cystic Carcinoma
}

National Cancer Institute

\section{Source}

National Cancer Institute. Laryngeal Adenoid Cystic Carcinoma. NCI Thesaurus. Code C9462.

A rare adenoid cystic carcinoma of the larynx. It usually arises from the supraglottic or subglottic area. It is characterized by slow progression and late distant metastases. 